\title{
The cell death response to the ROS inducer, cobalt chloride, in neuroblastoma cell lines according to p53 status
}

\author{
CHRISTOPHE STENGER *, THOMAS NAVES*, MIREILLE VERDIER and MARIE-HELENE RATINAUD \\ EA 3842 Homeostasie Cellulaire et Pathologies, Faculté de Médecine, \\ 2 Rue du Docteur Marcland, 87025 Limoges Cedex, France
}

Received February 28, 2011; Accepted April 7, 2011

DOI: $10.3892 /$ ijo.2011.1083

\begin{abstract}
Cobalt chloride $\left(\mathrm{CoCl}_{2}\right)$, a hypoxia-mimetic agent, induces reactive oxygen species (ROS) generation, leading to cell death. Divergent data have been reported concerning p53 implication in this apoptotic mechanism. In this study, we studied cobalt-induced cell death in neuroblastoma cell lines carrying wild-type (WT) p53 ( $S H S Y 5 Y$ ) and a mutated DNA-binding domain p53 $[\operatorname{SKNBE}(2 c)] . \mathrm{CoCl}_{2}$ induced an upregulation of p53, p21 and PUMA expression in WT cells but not in $S K N B E(2 c)$. In $S H S Y 5 Y$ cells, p53 serine-15 phosphorylation appeared early $(6 \mathrm{~h})$ in the mitochondria, and also in the nucleus after $12 \mathrm{~h}$. In contrast, in $\operatorname{SKNBE}(2 c)$ cells, the slight nuclear signal disappeared with $\mathrm{CoCl}_{2}$ treatment. In SHSY5Y cells, a mitochondrial pathway dependent on caspases [collapse of mitochondrial transmembrane potential $\left(\Delta \Psi_{\mathrm{mt}}\right)$, caspase 3 and 9 activation], was activated in a time-dependent manner. $S K N B E(2 c)$ cells exhibited a delay in the cell death executive phase linked to a caspase-independent pathway, involving apoptosis inducing factor nuclear translocation, but also an autophagic process attested by LC3-II expression and cathepsin-B activation. The downregulation of p53 in SHSY5Y cells by siRNA induced a cell death pathway related to the one observed in $\operatorname{SKNBE}(2 c)$ cells. Finally, $\mathrm{CoCl}_{2}$ induced time-dependent canonical p53 mitochondrial apoptosis in the WT p53 cell line, and caspase-independent cell death in cells with a mutated or $\mathrm{KO}$ p53.
\end{abstract}

\section{Introduction}

Many metallic molecules are involved in compounds with varied biological functions, such as vitamin B12, which contains cobalt. At millimolar doses, cobalt chloride $\left(\mathrm{CoCl}_{2}\right)$ can mimic

Correspondence to: Dr Marie-Helene Ratinaud, EA 3842 Faculté de Médecine, 2 Rue du Docteur Marcland, 87025 Limoges Cedex, France

E-mail: marie-helene.ratinaud@unilim.fr

${ }^{*}$ Contributed equally

Key words: apoptosis, autophagy, hypoxia mimetic, reactive oxygen species at least partially the effects of hypoxic agents, as it interacts with HIF-1 $\alpha$, and prevents its degradation by prolyl hydroxylase $(1,2)$. In addition, it generates reactive oxygen species (ROS) (3) through various mechanisms. There is some evidence that ROS production acts directly on mitochondrial function (4), inducing a mitochondrial transmembrane potential $\left(\Delta \Psi_{\mathrm{mt}}\right)$ collapse in various cells $(5,6)$. Nevertheless, the signaling pathway remains controversial and there is some debate concerning $\mathrm{CoCl}_{2}$, which can activate both the intrinsic $(7)$ and the extrinsic $(8,9)$ cell death pathways.

In numerous metal-induced oxidative stresses including $\mathrm{CoCl}_{2}$, p53 is implicated in transcriptional activating or in repressing numerous target genes, such as p21, Bax, PUMA. In response to ROS damage, p53 is stabilized by post-translational modifications, which regulate its trafficking and distribution to different organelles $(3,10,11)$. The phosphorylation in the $\mathrm{N}$-terminal transactivation domain (TAD) is one of these modifications, which occur in response to stress, and are very important for p53 stabilization $(12,13)$. The phosphorylation of Ser15 occurs rapidly in response to diverse stimuli, including ROS and appears to be a 'priming event' for subsequent series of modifications such as phosphorylation of Thr18 (14). p53 has been described as a protein whose functions depend on its nuclear accumulation (15). Nevertheless, some studies have indicated that p53 moves to the mitochondria in response to stress (16), in a monoubiquitylation form preventing its proteasomal degradation (17). Consequently, mitochondrial signaling is activated leading to a $\Delta \Psi_{\mathrm{mt}}$ collapse, resulting in the cytoplasmic release of effectors (cytochrome c, pro-caspase-9, etc.) constituting the apoptosome, which promotes caspase-9 and then caspase- 3 activation, then a downstream cascade referred to as caspase-dependent cell death (18). The involvement of the apoptosis inducing factor (AIF) in mitochondrial downstream pathways, in the absence of caspase activation has been investigated extensively (19). The involvement of AIF has been described in numerous models of cell death including metals, such as As203 (20) or $\mathrm{CoCl}_{2}$ (2,6). Moreover, data have suggested that caspase-independent cell death can also correspond to an autophagic process (21). It has become accepted that besides its role in cell survival, autophagy also leads to cell death. ROS can induce different pathways of autophagy according to their levels (22). Drastic oxidative stress leads to autophagic or necrotic cell death (23). Today, the ability of 
ROS to provoke autophagy-induced cell death and regulation of molecular mechanisms remains mainly unknown (21).

Today, the accumulation of p53 protein following oxidative stresses is relatively well characterized, but there are no studies concerning their effect on functional consequences in neuroblastoma cells according to the status of $\mathrm{p} 53$. We studied the cell death pathway activated by the ROS inducer, $\mathrm{CoCl}_{2}$, in two neuroblastoma lines: $\operatorname{SKNBE}(2 c)$ cells harboring a mutated-DNA-binding p53 domain and SHSY5Y cells carrying wild-type (WT) p53 or having RNA interference-mediated knockdown of p53. Taken together, these data suggest that the ROS inducer, $\mathrm{CoCl}_{2}$, activated a p53 mitochondrial apoptosis in the WT p53 neuroblastoma cell line. A caspase-independent cell death was observed in the p53 mutated cell line through cytoplasmic AIF release and autophagic process, as well as in SHSY5Y cells, with similar features, when p53 was knocked down.

\section{Materials and methods}

Chemicals and reagents. $\mathrm{CoCl}_{2}$ was supplied as a sterile ready-to-use 0.1 M stock solution (Sigma, France). Primary antibodies: Mouse monoclonal anti-Bax- $\alpha$ (clone-3) was purchased from BD Biosciences, rabbit anti-p21 (C-19), anti $\alpha$-tubulin (TU-02), anti-TOM20, an external membrane mitochondrial protein (FL-145), anti-MAP-LC3-II (H-50), anti-AIF (H-300), and anti-p53 (Bp53-12) antibodies were purchased from Santa Cruz (Tebu-bio, France). Rabbit antiPUMA and mouse monoclonal anti-phospho-p53 (Ser15) (clone 16G8) antibodies were obtained from Cell Signalling (Ozyme, France). For Western blotting revelation, HRP-labeled secondary antibodies were purchased from DakoCytomation (France) and secondary Alexa fluor $488^{\mathrm{TM}}$ and $594^{\mathrm{TM}}$ conjugated antibodies (diluted 1:1000) were provided from Molecular Probes (Invitrogen, France).

Cell culture and viability. The human neuroblastoma cell lines $S H S Y 5 Y$ (WTp53) and $S K N B E(2 c)$ (mutated p53) were a gift from Professor Javier S. Castresana, Navarre University (Spain). Cell lines were cultured at $37^{\circ} \mathrm{C}$, in a $5 \% \mathrm{CO}_{2}$ humidified atmosphere, in RPMI-1640 medium (Eurobio, France) supplemented with 10\% FCS (Invitrogen), $10 \mathrm{mM}$ sodium pyruvate (Invitrogen), $2 \mathrm{mM}$ glutamin (Invitrogen, France) and an antibiotic mixture (penicillin/streptomycin, Sigma, France). The effect of $\mathrm{CoCl}_{2}$ on $\mathrm{SHSY5Y}$ and $\operatorname{SKNBE}(2 c)$ cell viability, was determined by trypan blue exclusion (Sigma, France). Cells were plated into a 96 -well plate at $5 \times 10^{4}$ cells/ well in $100 \mu \mathrm{l}$ RPMI-1640 and incubated at $37^{\circ} \mathrm{C}, 5 \% \mathrm{CO}_{2}$ for $24 \mathrm{~h}$. When approximately $80 \%$ confluence was reached, cells were treated or not with $500 \mu \mathrm{M} \mathrm{CoCl}_{2}$, for various times and numbered at each kinetic time-point.

siRNA transfection assay. Transfection assay was carried out with the SignalSilence ${ }^{\circledR}$ p53 siRNA kit (human specific) from Cell Signaling Technology, containing a pre-validated siRNA duplex specific for p53 RNAm (siRNA ${ }^{\mathrm{p} 53}$ ). The lipid-mediated transfection reagent (TransIT-TKO ${ }^{\circledR}$ ) was purchased from Mirus and used for all transfection experiments. For control conditions, transfection reagent was used either alone without siRNAs, or with scramble siRNA coupled with fluorescein
(siRNA ${ }^{\text {fluo }}$ ). After $24 \mathrm{~h}$ of culture, cells were washed (approximately $50 \%$ confluence) and transfection mixture was added according to manufacturer's instructions for $24 \mathrm{~h}$ at $37^{\circ} \mathrm{C}, 5 \%$ $\mathrm{CO}_{2}$. After 24-h transfection, the mixture containing siRNAs was discarded and fresh serum-containing medium with or without $500 \mu \mathrm{M} \mathrm{CoCl}_{2}$ was added to the cells for various times.

Immunofluorescence and confocal microscopy analysis. Both cell lines were grown on glass coverslips (14-mm diameter, Menzel-Gläser, VWR, France) in a 24-well plate for $24 \mathrm{~h}$ in RPMI-1640 medium supplemented with or without $500 \mu \mathrm{M}$ $\mathrm{CoCl}_{2}$ for different times. Cells were then fixed with $4 \%$ PFA-PBS for $15 \mathrm{~min}$ at room temperature, and permeabilized with methanol for $10 \mathrm{~min}$ at $-20^{\circ} \mathrm{C}$. A blocking step was performed with PBS-0.1\% Triton X100-5\% goat serum for $1 \mathrm{~h}$. Cells were then incubated with polyclonal rabbit primary antibody to ATG12 or LC3B (1/150e), diluted in PBS-0.1\% Triton $\mathrm{X} 100$, overnight at $4^{\circ} \mathrm{C}$ under gentle agitation. After washing, cells were incubated with the appropriate AlexaFluor ${ }^{\mathrm{TM}}$ conjugated secondary antibody for $1 \mathrm{~h}$ at room temperature in the dark and counterstained with TOPRO- $3^{\mathrm{TM}}$. Labeling analysis was carried out using a confocal microscope (Zeiss Axiovert-200, Göttingen, Germany) equipped with a laserscanning confocal imaging system (Zeiss LSM 510 META).

$\Delta \Psi_{m t}$ and plasma membrane integrity analysis. $\Delta \Psi_{\mathrm{mt}}$ and plasma membrane integrity were assessed using JC-1 and TOPRO- $3^{\mathrm{TM}}$ probes, respectively, according to Zuliani et al (24). Briefly, after stress, cells were collected and resuspended in $500 \mu \mathrm{l}$ of RPMI-1640 medium and stained for $30 \mathrm{~min}$ with $1 \mu \mathrm{g} / \mathrm{ml} \mathrm{JC}-1$ at $37^{\circ} \mathrm{C}$. Then $1 \mu \mathrm{M}$ TOPRO- $3^{\mathrm{TM}}$ was added and cells were immediately analyzed with a FACS ${ }^{\circledR}$ Vantage. JC-1 was excited with the $488 \mathrm{~nm}$ Argon laser and green fluorescence related to low $\Delta \Psi_{\mathrm{mt}}$ and orange fluorescence corresponding to high $\Delta \Psi_{\mathrm{mt}}$ were collected, while TOPRO-3 was excited with the Helium-Neon laser and red fluorescence was recorded. Three populations were defined corresponding to living cells (JC-1 $1^{\text {high}}$; TOPRO- $3^{\text {low }}$, necrotic or late apoptotic cells (JC-1 ${ }^{\text {low }}$;OPRO- $3^{\text {high }}$ ) and apoptotic cells (JC-1 ${ }^{\text {low }}$; TOPRO-3 $3^{\text {low })}$.

Caspase- 3, -9 and cathepsin B activity assays. Cells were then lysed in CHAPS buffer. The assays were performed as described previously (25). Peptide substrates (Bachem, Germany) for caspase-3 (Ac-DEVD-AMC), caspase-9 (Ac-LEHD-AMC) or cathepsin B (Z-RR-AMC) were added to each well at a final concentration of $5 \times 10^{-5} \mathrm{M}$. Caspase -3 , -9 (Ac-DEVD-CHO and Ac-LEHD-CHO) and cathepsin B (L-Trans-Epoxysuccinyl-IP-OH propylamide) inhibitors at $2.5 \mathrm{mM}$ were added $30 \mathrm{~min}$ before the substrate. The assay plates were incubated at $37^{\circ} \mathrm{C}$ for $2 \mathrm{~h}$ and fluorescence was measured with a microplate reader (Twinkle LB 970, Berthold, France). Activities were expressed in relative fluorescence units (RFU).

Western blotting. Protein lysates $(30 \mu \mathrm{g})$ of cell culture control or treated cells (500 $\mu \mathrm{M} \mathrm{CoCl}_{2}$ ) (floating and adherent cells) were separated by SDS-PAGE. After electrophoretic migration, proteins were electroblotted onto cellulose membranes. 
After a blocking step (TBS-1X containing 0.1\% Tween-20 and 5\% non-fat dry milk) membranes were incubated with specific antibodies and revealed with appropriate secondary HRP-conjugated antibodies. Blots were developed with Immobilon Western chemiluminescent HRP substrate from Millipore and analyzed with G-Box (Ozyme). Densitometric analyses were performed using an IMAGEJ software program (National Institutes of Health, Bethesda, http://rsb.info.nih. gov/ij/). Protein expression was determined in relative units with reference to tubulin expression.

Statistical analysis. The two-sided Student's-test was used to compare the differences between treated and untreated cells and between cell lines. A value of $\mathrm{p}<0.05$ was considered to be statistically significant, with the graduation $\mathrm{p}<0.05, \mathrm{p}<0.01$ and $\mathrm{p}<0.001$.

\section{Results}

$\mathrm{CoCl}_{2}$ treatment induced neuroblastoma cell death. $\mathrm{CoCl}_{2}$ has been reported to induce oxidative stress $(10,26)$ and cell death. In this study, we investigated the cytotoxic effect of $\mathrm{CoCl}_{2}$ on two neuroblastoma cell lines having a different p53 status: WT $(S H S Y 5 Y)$ and mutated p53 gene $[\operatorname{SKNBE}(2 c)]$. In an interval ranging from 2 to $24 \mathrm{~h}, 500 \mu \mathrm{M} \mathrm{CoCl}_{2}$ exposures (Table I) induced a cytotoxic effect evaluated by the trypan blue exclusion assay. In the $S H S Y 5 Y$ cell line, viability decreased from $12 \mathrm{~h} \mathrm{CoCl}_{2}$ exposure whereas in $\operatorname{SKNBE}(2 c)$ cells the viability reduction appeared later. After $24 \mathrm{~h}$ of treatment, cell viability was affected more significantly in the $S H S Y 5 Y$ cells (reduced to about $75 \%$ ) than in the $S K N B E(2 c)$ cells (decreased by $50 \%$ ). These results correlate with morphological changes such as cell shrinkage (data not shown).

$\mathrm{CoCl}_{2}$ enhanced p53 levels in SHSY5Y cells but not in $\operatorname{SKNBE}(2 c)$ cells. In numerous metal-induced oxidative stresses, p53 is implicated in cell signaling, thus we studied this using $S K N B E(2 c)$ and SHSY5Y cells. Previously, we validated the mutation of exon 5 in the $\operatorname{SKNBE}(2 c)$ cell line, encoding the DNA binding domain of p53. As expected, the p53 codon 135-TGC (cysteine) for WT SHSY5Y cells (data not shown), became codon TTC (phenylalanine) for $S K N B E(2 c)$ cells (27). SHSY5Y cells (WTp53) and $S K N B E(2 c)$ (mutated p53) cells were exposed for various times ( 0 to $24 \mathrm{~h})$ to the drug $\left(500 \mu \mathrm{M} \mathrm{CoCl}_{2}\right)$ and p53 expression was studied (Fig. 1A). The p53 level in control SHSY5Y cells increased significantly from $6 \mathrm{~h} \mathrm{CoCl}_{2}$ treatment (about 100\%, p<0.05), peaked at $12 \mathrm{~h}$ and then decreased at $24 \mathrm{~h}$, which correlated with massive cell death. While p53 was detected in untreated $\operatorname{SKNBE}(2 c)$ cells, which is in agreement with other data (27), in the presence of $\mathrm{CoCl}_{2}$ its level was significantly abolished in a time-dependent manner $(\mathrm{p}<0.05)$.

p53 phosphorylation on Ser15 after $\mathrm{CoCl}_{2}$ treatment in both cell lines. Data were completed by immunofluorescence analyses of p53 phosphorylation at the Ser15 residue (phospho-p53 Ser15) (Fig. 1B). As expected, in control SHSY5Y cells, a weak and non-specific green fluorescence was observed. After $6 \mathrm{~h}$ of $\mathrm{CoCl}_{2}$ treatment, a faint expression of phospho-p53 Ser15 was detected in the nucleus, whereas a bright cytoplasmic green fluorescence appeared corresponding to mitochondrial
Table I. Cytotoxic effect of $500 \mu \mathrm{M} \mathrm{CoCl}_{2}$, after 0 to $24 \mathrm{~h}$ of treatment on neuroblastoma $S H S Y 5 Y$ and $S K N B E(2 c)$ cell lines.

\begin{tabular}{llc}
\hline Exposure time (h) & $\begin{array}{c}\text { SHSY5Y cells } \\
\text { Percentage of cell viability }\end{array}$ & \begin{tabular}{c}
$S K N B E(2 c)$ cells \\
\cline { 2 - 3 }
\end{tabular} \\
\cline { 2 - 3 } 0 & $97.35 \pm 0.97$ & $97.56 \pm 0.62$ \\
2 & $96.73 \pm 1.39$ & $95.92 \pm 1.26$ \\
6 & $96.89 \pm 1.31$ & $96.18 \pm 1.50$ \\
12 & $78.09 \pm 1.81$ & $96.10 \pm 1.83$ \\
18 & $67.68 \pm 6.57$ & $74.10 \pm 3.87$ \\
24 & $23.43 \pm 2.21$ & $57.93 \pm 3.47$ \\
\hline
\end{tabular}

The cytotoxic effect was estimated by trypan-blue exclusion assay, reflecting cell viability. Data represent the means \pm SD of at least 3 independent experiments.

staining: A yellow color appeared in the merge microphotography (approximately 30\% of organelles). After $12 \mathrm{~h} \mathrm{CoCl}_{2}$ treatment, the green signal was present in the mitochondria (punctuated fluorescence) and mainly in the nucleus (granular staining), but at $24 \mathrm{~h}$, phospho-p53 Ser15 became undetectable (data not shown). In contrast, a weak expression of phosphop53 Ser15 was observed in the untreated $\operatorname{SKNBE}(2 c)$ cells and disappeared in the $\mathrm{CoCl}_{2}$-treated cells.

$\mathrm{CoCl}_{2}$ induced $\mathrm{p} 21$ and PUMA accumulation in SHSY5Y but not in $\operatorname{SKNBE}(2 c)$ cells. Active phosphorylated p53 controls the transcription of several genes, such as $p 21$, Bax and PUMA. Corresponding proteins were analyzed by Western blotting in both neuroblastoma lines. In SHSY5Y cells (Fig. 2), levels of p21 and PUMA increased following $6 \mathrm{~h}$ of $\mathrm{CoCl}_{2}$ treatment and diminished at $24 \mathrm{~h}$, concomitantly to loss of cell viability, whereas Bax level was slightly modified. Concerning $S K N B E(2 c)$ cells, an expression was detected in the control cells only for Bax. After $\mathrm{CoCl}_{2}$ exposure a significant $\mathrm{p} 21$ expression appeared after $6 \mathrm{~h}(\mathrm{p}<0.005)$, whereas a minor enhancement appeared for Bax and PUMA (not significant), which was significantly abolished in a time-dependent manner ( $\mathrm{p}<0.05$ from $12 \mathrm{~h}$ for PUMA and only at $24 \mathrm{~h}$ for Bax).

$\mathrm{CoCl}_{2}$ induced a different time-dependent $\Delta \Psi_{m t}$ collapse and caspase -3 , and -9 activities. Modification of $\left(\Delta \Psi_{\mathrm{mt}}\right)$ generally constitutes p53 downstream signaling. Thus, after induced stress by $\mathrm{CoCl}_{2}, \Delta \Psi_{\mathrm{mt}}$ was examined in both cell lines according to time kinetics (Fig. 3A). In both control cell lines $(0 \mathrm{~h})$, almost all exhibited a high $\Delta \Psi_{\mathrm{mt}}$ and cells were intact $(\geq 90 \%)$, while the percentage of cells with mitochondrial failure were very low $(<5 \%)$. Under $500 \mu \mathrm{M} \mathrm{CoCl}_{2}$ treatment, SHSY5Y cells showed a time-dependent $\Delta \Psi_{\mathrm{mt}}$ collapse (about $15 \%) 6 \mathrm{~h}$ after treatment, which became drastic at $12 \mathrm{~h}(>50 \%$ low potential and $25 \%$ late apoptotic/necrotic cells). After $24-\mathrm{h}$ exposure, only a residual percentage of cells remained intact (about 20\%). In contrast, $\Delta \Psi_{\mathrm{mt}}$ was almost unchanged until $12 \mathrm{~h}$ in $\operatorname{SKNBE}(2 c)$ cells, then an obvious $\Delta \Psi_{\mathrm{mt}}$ collapse and increased plasma membrane permeability occurred from $24 \mathrm{~h}$ $\mathrm{CoCl}_{2}$ treatment (nevertheless $40 \%$ of cells remained intact). 
A
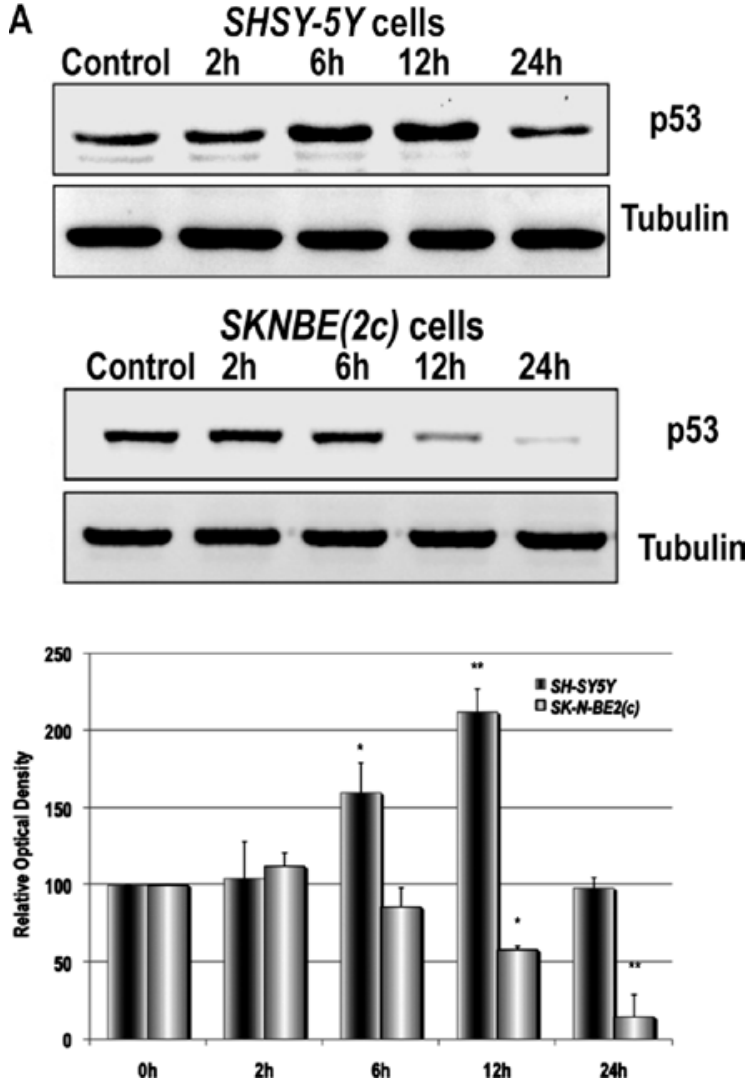

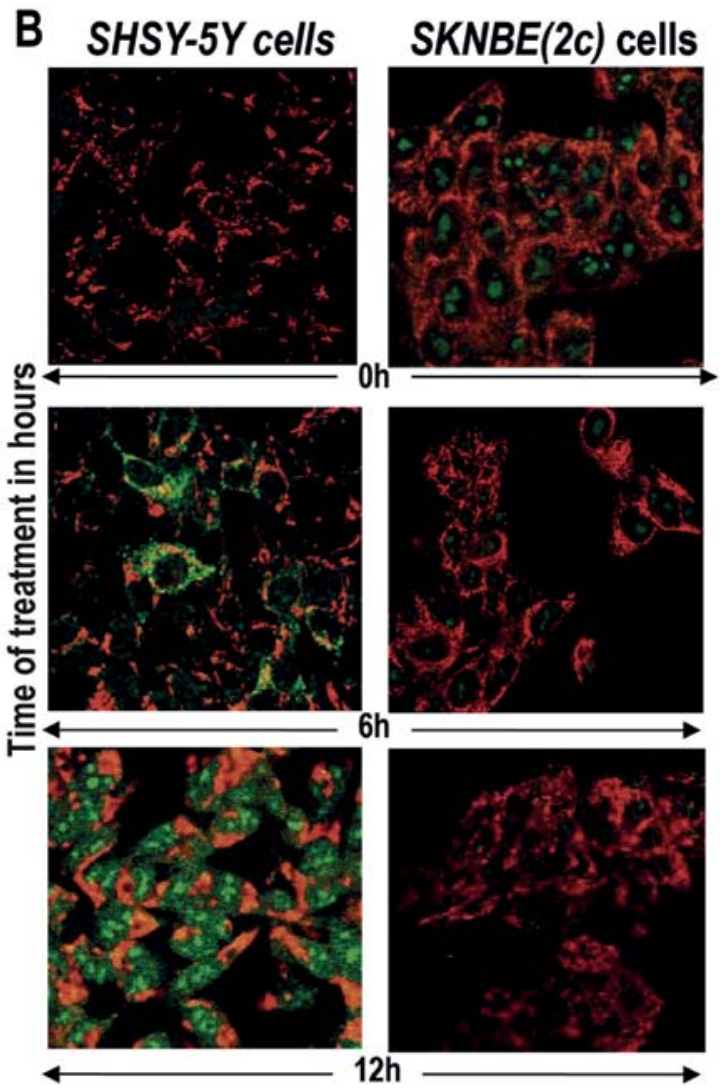

Figure 1. (A) $\mathrm{CoCl}_{2}$ induced a time-dependent increase in p53 levels in $S H S Y 5 Y$ cells and a decrease in $S K N B E(2 c)$ cells. Both cell lines were treated with $500 \mu \mathrm{M} \mathrm{CoCl}_{2}$ for the indicated time and cell lysates were analyzed for p53 expression by Western blotting. Protein expression was quantified by densitometry relative to the loading control tubulin and untreated controls. (B) $\mathrm{CoCl}_{2}$ treatment raised p53 Ser15-phosphorylation in $S H S Y 5 Y$ cells, but not in $S K N B E(2 c)$ cells After the indicated time of drug exposure, immunolabeling and localization of phospho-Ser15-p53 was performed using appropriate AlexaFluor ${ }^{\mathrm{TM}}$-conjugated secondary antibody, conferring a green fluorescence, whereas the mitochondria appeared red.

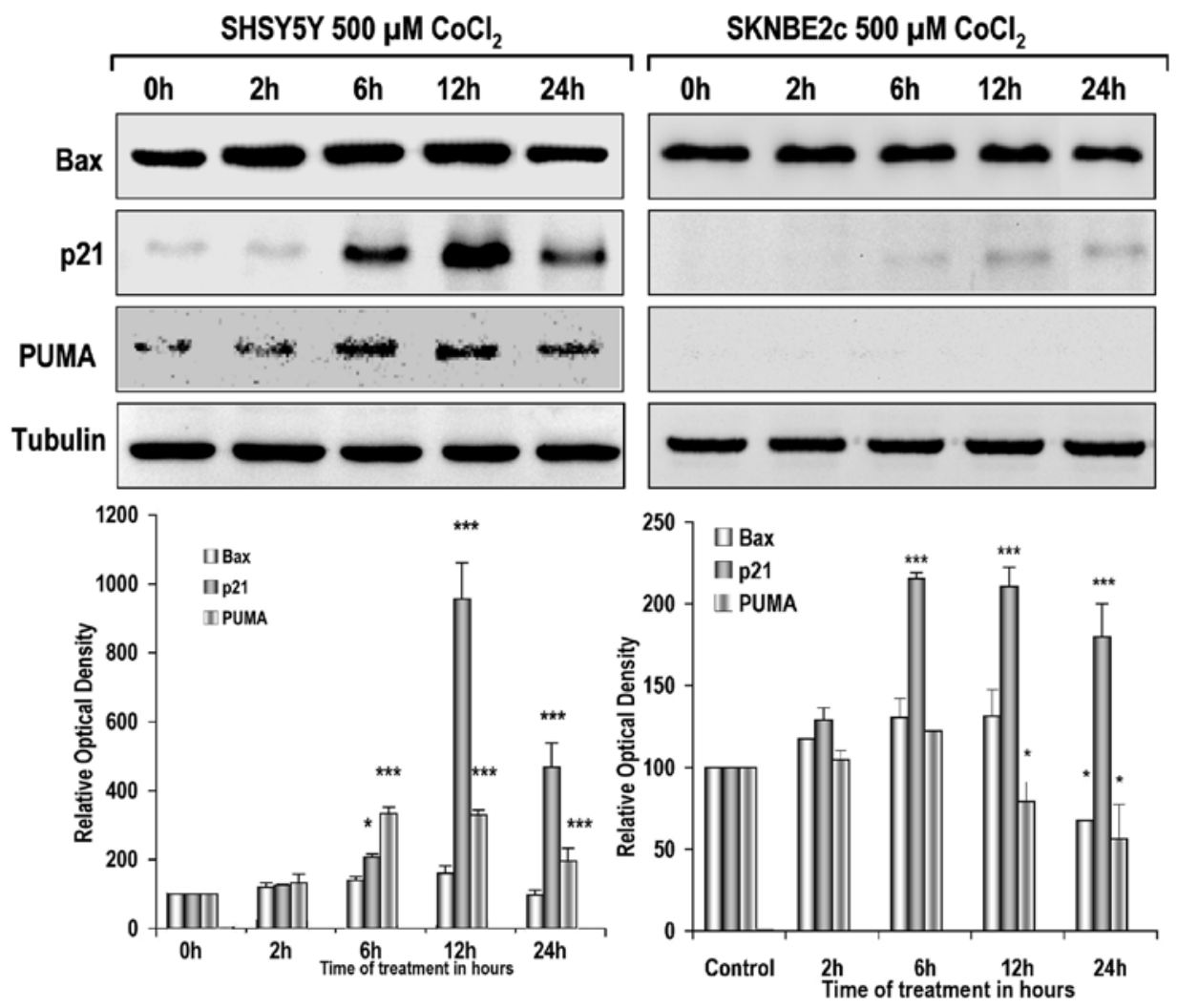

Figure 2. p21, PUMA and Bax were enhanced after treatment with $500 \mu \mathrm{M} \mathrm{CoCl}_{2}$ in $S H S Y 5 Y$ but not in $S K N B E(2 c)$ cells. After $500 \mu \mathrm{M}_{\text {of }}$ CoCl 2 exposure, cell lysates were analyzed by Western blotting for p21, PUMA and Bax expression with appropriate antibodies. Densitometric analyses were determined in relative units with reference to tubulin expression. ${ }^{*} \mathrm{p}<0.05,{ }^{* * * *} \mathrm{p}<0.001$ 

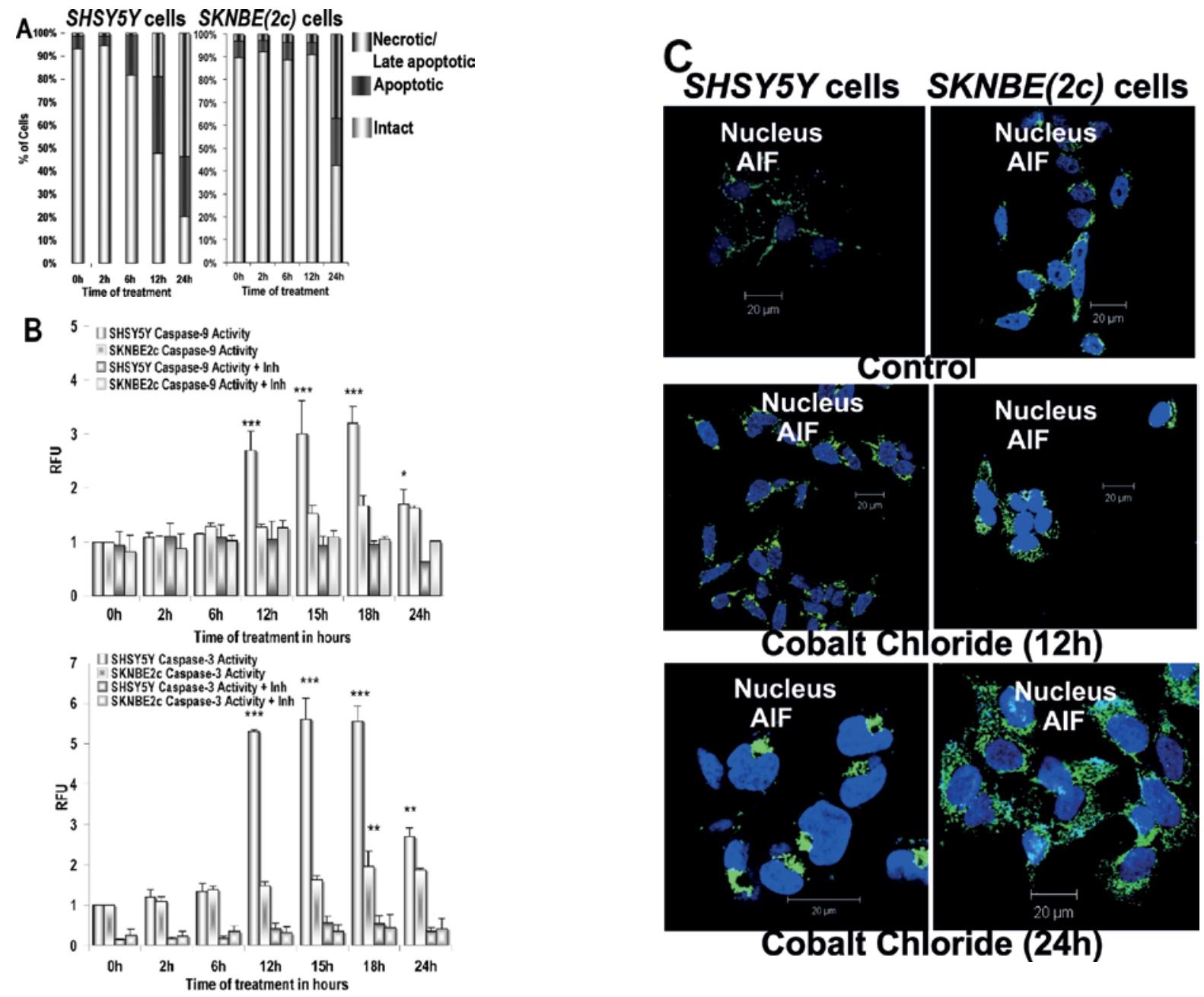

Cobalt chloride (12h)

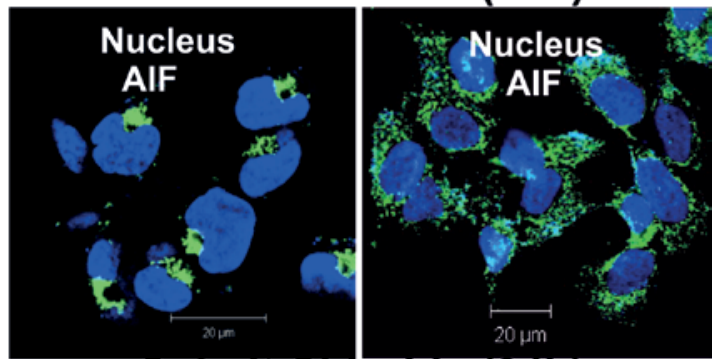

Cobalt Chloride (24h)

Figure 3. (A) The strong modification in $S H S Y 5 Y$ cells, after $12 \mathrm{~h}$ of $\mathrm{CoCl}_{2}$ exposure in $\Delta \Psi_{\mathrm{mt}}$ collapse and membrane permeability contrasted with the slight changes observed in $\operatorname{SKNBE}(2 c)$ cells, in which significant modifications appeared only after $24 \mathrm{~h}$. After cytometric analyses, three subpopulations were defined corresponding to intact cells ( $\mathrm{JC}^{\text {high }}$ TOPRO-3 $\left.{ }^{\text {low }}\right)$, apoptotic cells $\left(\mathrm{JC} 1^{\text {low }}\right.$ TOPRO-3 ${ }^{\text {low }}$ ) and necrotic/late apoptotic cells $\left(\mathrm{JC} 1^{\text {low }} \mathrm{TOPRO}^{\text {high }}\right) .(\mathrm{B}) \mathrm{CoCl}_{2}$ treatment strongly enhanced caspase-3 and -9 activity (evaluated with a fluorometer and expressed in RFUs) in SHSY5Y cells following 12-h drug exposure, whereas $\operatorname{SKNBE}(2 c)$ exhibited only a weak and late enhancement of activities. (C) The mitochondrial AIF localization was analyzed after immunofluorescence staining with specific antibodies (green color), and counter-staining of nuclei with TOPRO-3 in two neuroblastoma cells. In SHSY5Y cells, regardless of exposure time to $500 \mu \mathrm{M} \mathrm{CoCl}_{2}$, AIF remained located in the cytoplasmic compartment, whereas in $S K N B E(2 c)$ cells, green AIF fluorescence in the nuclei appeared at $12 \mathrm{~h}$ and was significantly detected at $24 \mathrm{~h} .{ }^{*} \mathrm{p}<0.05,{ }^{* *} \mathrm{p}<0.01,{ }^{* * *} \mathrm{p}<0.001$.
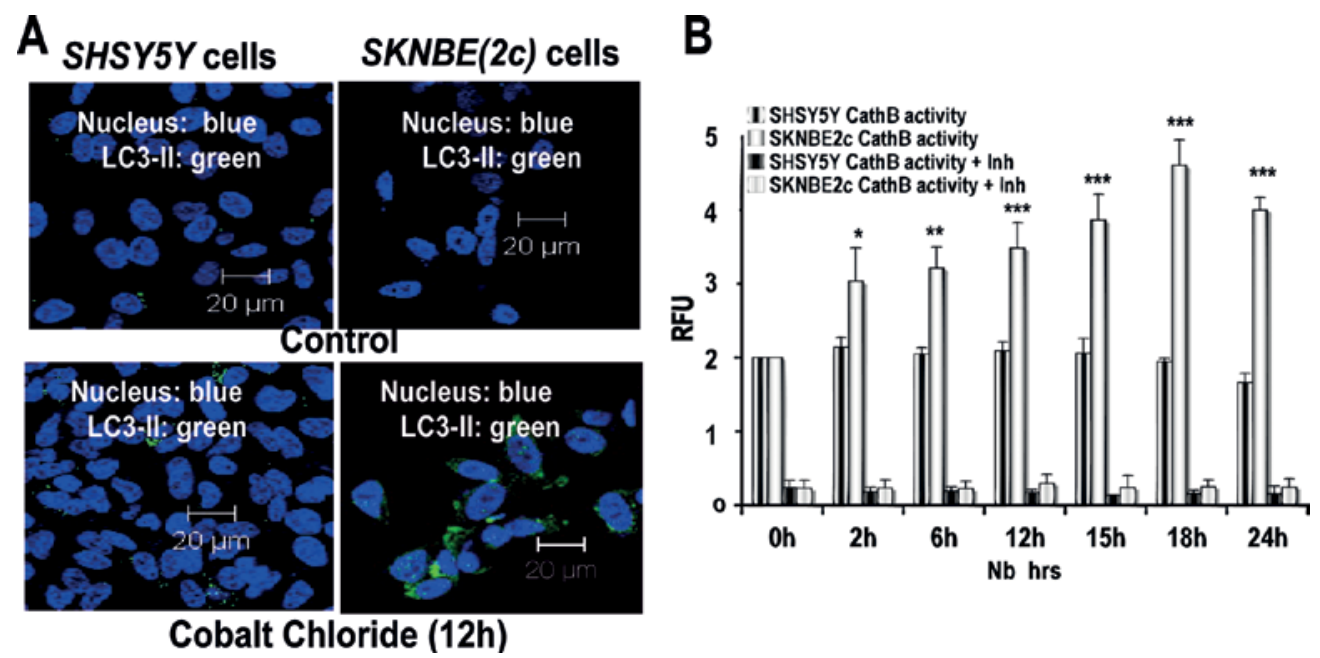

Figure 4. (A) MAP-LC3-II specific expression following $\mathrm{CoCl}_{2}$ exposure was detected in the $S K N B E(2 c)$ cells but not in the $S H S Y 5 Y$ cells. After the indicated drug treatment, immunofluorescence staining was performed with specific MAP-LC3 antibodies (green color), and counter-staining of nuclei with TOPRO-3 by confocal laser scanning microscopy. (B) $\mathrm{CoCl}_{2}$ treatment enhanced cathepsin B activity in $\operatorname{SKNBE}(2 c)$ cells, whereas such activity was not observed in the SHSY5Y line. After various times of $500 \mu \mathrm{M} \mathrm{CoCl}_{2}$ exposure, CHAPS cell line lysates were incubated with cathepsin B specific substrate and in the presence of inhibitors. Fluorescence was measured with a fluorometer and activities were expressed in RFUs. ${ }^{*} \mathrm{p}<0.05,{ }^{* *} \mathrm{p}<0.01,{ }^{* * *} \mathrm{p}<0.001$. 
A

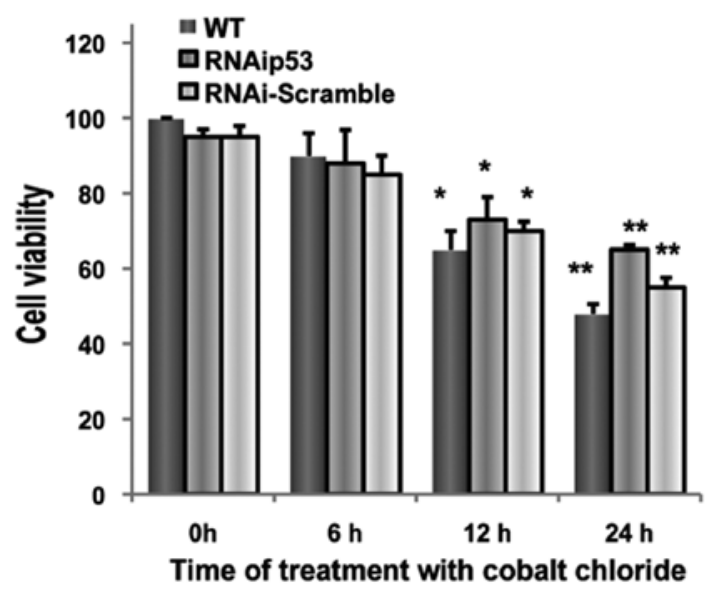

B
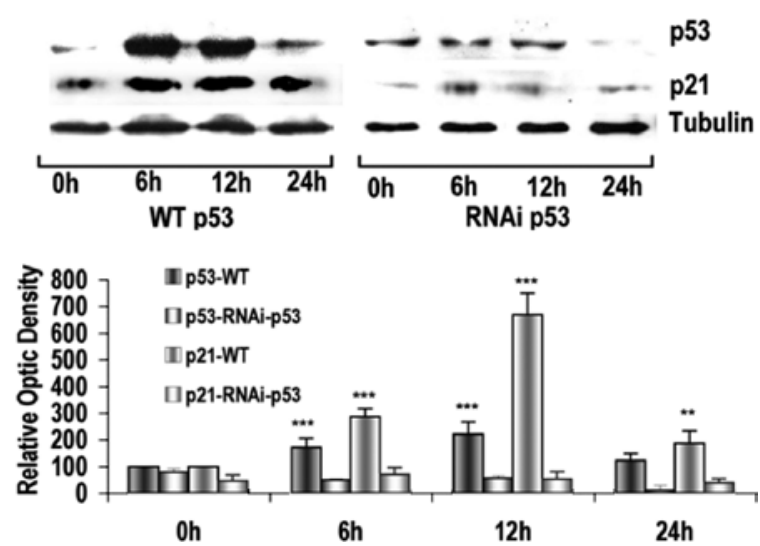

C
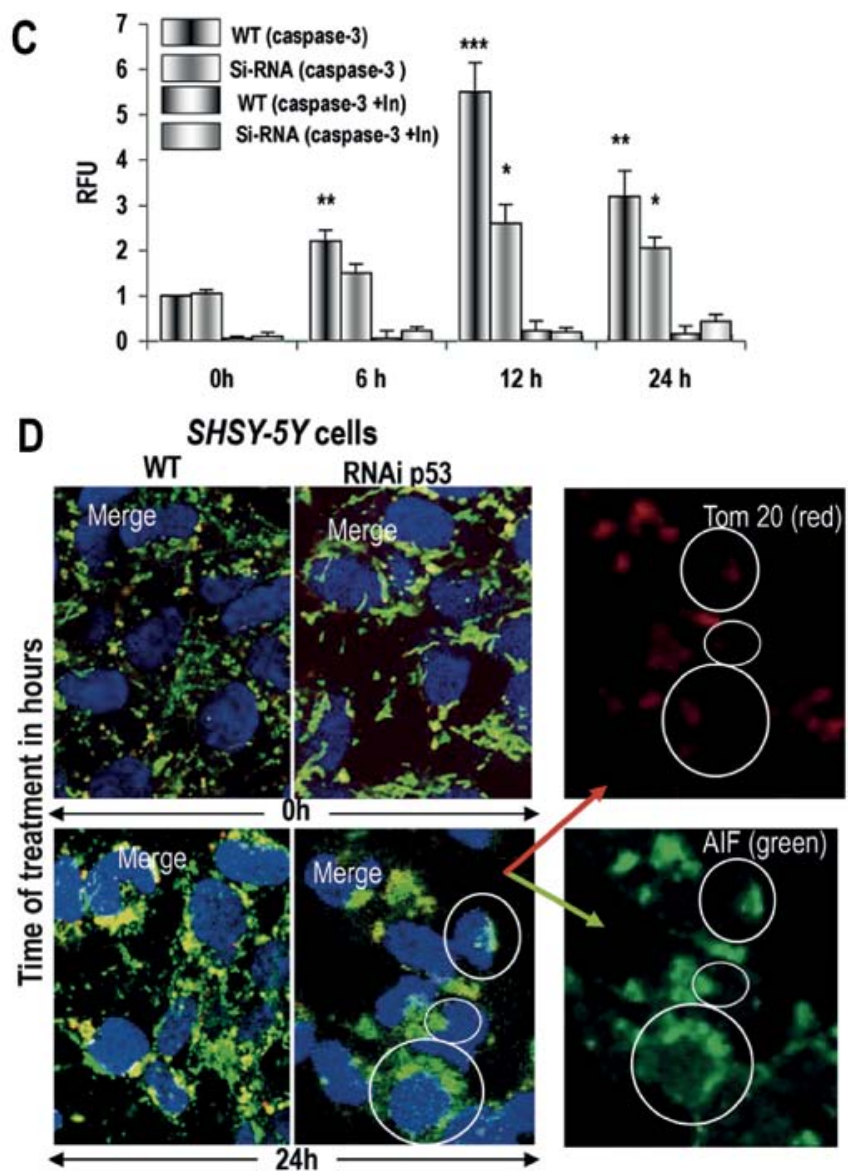

Figure 5. $\mathrm{CoCl}_{2}$ induced a caspase-independent cell death in RNAi p53-transfected SHSY5Y cells. (A) Cell viability, checked using the trypan blue exclusion test, diminished for the three conditions during the $\mathrm{CoCl}_{2}$ treatment, but RNAip53 cells exhibited cell viability higher than the WT p53 SHSY5Y cells. (B) The efficiency of p53 silencing was controlled by monitoring p53 and p21 expression (Western blot). As expected, it remained low in p53-silenced cells, during $\mathrm{CoCl}_{2}$ treatment. (C) p53 siRNA-transfected cells exhibited a reduced enhancement of caspase 3 activity compared to WT p53 cells. The caspase-3 activity was measured with a specific substrate with reference to the inhibitor, as previously described. (D) RNAip53-transfected cells showed a translocation of AIF to the nucleus at $24 \mathrm{~h}$ of $\mathrm{CoCl}_{2}$ exposure, whereas WT p53 cells kept the AIF protein in the mitochondria. AIF expression and localization were monitored by confocal microscopy after staining with specific antibodies (green color for AIF), mitochondria with TOM20 (red color) and nuclei were counter-stained with TOPRO-3 (blue color). ${ }^{*} \mathrm{p}<0.05,{ }^{* *} \mathrm{p}<0.01,{ }^{* * * *} \mathrm{p}<0.001$.

Caspase-3 and -9 constitute mitochondrial downstream effectors. In both the SHSY5Y and SKNBE(2c) cells, the specific activities were low in the control in the presence of inhibitors (Fig. 3B). After 12-h $\mathrm{CoCl}_{2}$ exposure, caspase-9 activity was enhanced in SHSY5Y cells $(\mathrm{p}<0.005)$ followed by a downregulation at $24 \mathrm{~h}$, whereas caspase-3 activity was highly upregulated at $12 \mathrm{~h}(5.5$-fold, $\mathrm{p}<0.005)$ and was maintained high until $24 \mathrm{~h}$ (x3), corresponding to a final execution of cell death. In contrast, in $\operatorname{SKNBE}(2 c)$ cells, both caspase activities increased slightly after $24 \mathrm{~h}$ of cobalt treatment $(\mathrm{p}<0.05)$.

$\mathrm{CoCl}_{2}$ exposure induced cytoplasmic release of AIF, only in $S K N B E(2 c)$ cells. AIF is a protein released from the mitochondria in caspase-independent cell death (28). As caspase-3 and -9 activities were very weakly enhanced during the later stages in $S K N B E(2 c)$ cells, we investigated the role of AIF in cell death signaling due to $\mathrm{CoCl}_{2}$ exposure (Fig. 3C). Both in the control and treated SHSY5Y cells, AIF remained located in the cytoplasmic compartment (i.e. mitochondria), whereas in $\operatorname{SKNBE}(2 c)$ cells a green AIF fluorescence in the nucleus appeared after $12 \mathrm{~h}$ and was significantly detected at $24 \mathrm{~h}$.
$\mathrm{CoCl}_{2}$ exposure induced MAP-LC3-II expression and cathepsin $B$ activity only in $\operatorname{SKNBE}(2 c)$ cells. We monitored MAP-LC3-II localization, an autophagic marker activated during the process (29), which could explain the delay in the death response of $S K N B E(2 c)$ cells. A faint green fluorescence was detected both in the control SHSY5Y and SKNBE $(2 c)$ cells (Fig. 4A) corresponding to non-specific staining or a very low basal level of autophagy. After $12 \mathrm{~h}$ of $\mathrm{CoCl}_{2}$ exposure, MAP-LC3-II positive staining appeared in some SHSY5Y cells, whereas $\operatorname{SKNBE}(2 c)$ cells showed a perinuclear bright green fluorescence. In the same way, the cathepsin B activity, a main lysosomal aspartic protease, remained slightly modified in SHSY5Y cells (Fig. 4B). On the contrary in $\operatorname{SKNBE}(2 c)$ cells, the activity was 2 -fold and peaked at $18 \mathrm{~h}$.

The response to $\mathrm{CoCl}_{2}$ is modified in RNAi p53-transfected SHSY5Y cells. To explore the implication of p53 in the activated cell death pathway by $\mathrm{CoCl}_{2}$, we monitored the signaling in the SHSY5Y cell line with the same stress but with p53 expression silenced by siRNA. First, several controls were achieved, checking that the viability was similar whatever the 
experimental conditions (control, RNAi-p53, p53-scramble) in the absence of $\mathrm{CoCl}_{2}$. In the same way the lipid-mediated transfection agent TransIT-TKO had no effect (data not shown). After the drug-inducing stress, as expected, the viability diminished gradually during treatment (Fig. 5A). After $24 \mathrm{~h}$, the percentage of viability of RNAip 53 cells was higher than in p53WT SHSY5Y cells ( $\mathrm{p}=0.04)$.

As shown in Fig. 1, in the presence of $\mathrm{CoCl}_{2}$, the level of p53 in SYSH5Y cells (WT p53) peaked after $12 \mathrm{~h}$ and became similar to the control after $24 \mathrm{~h}$. For RNAip53-transfected cells, the level of p53 remained low for 6,12 and $24 \mathrm{~h}$ of $\mathrm{CoCl}_{2}$ treatment (Fig. 5B). In a similar manner, one of the transcriptional targets of p21 was upregulated in WT SHSY5Y cells following 6,12 and $24 \mathrm{~h}$ of $500 \mu \mathrm{M} \mathrm{CoCl}_{2}$ exposure, and it was reduced after transfection with RNAip53 (Fig. 5B), confirming the transfection efficiency. The $\Delta \Psi_{\mathrm{mt}}$ collapse following $\mathrm{CoCl}_{2}$ exposure decreased in a moderate manner in RNAip53-transfected cells [similar to $S K N B E(2 c)$ cells] comparatively to WT SHSY5Y cells (data not shown). The very significant upregulation of caspase-3 activity in the presence of $\mathrm{CoCl}_{2}$ in WT p53 cells (6-fold) was reduced in RNAip53-transfected cells being only twice enhanced after $12 \mathrm{~h}$ of treatment (Fig. 5C) suggesting a caspase-independent death. Thus, the AIF localization (green fluorescence) was analyzed simultaneously with DNA (blue fluorescence) and mitochondria with an antibody against TOM20 (red color) (Fig. 5D). After $24 \mathrm{~h}$ of $\mathrm{CoCl}_{2}$ treatment, part of AIF was present in the nucleus and cytoplasm in RNAip53-transfected cells corresponding to an AIF release, whereas in WT cells a co-localization of AIF with the mitochondria (yellow color) was observed.

\section{Discussion}

$\mathrm{CoCl}_{2}$ can mimic hypoxic responses in many respects, including ROS generation. According to the severity of the stress encountered, ROS induce damage to components, such as nucleic acids, leading to p53 recruitment and the mitochondrial cell death pathway (also known as intrinsic cell death). Nevertheless, the implication of p53 varies in many different types of cells $(5,30)$ and the death receptordependent (extrinsic) pathway is also recruited (7). The cell death pathway induced by $\mathrm{CoCl}_{2}$ remains variable, especially concerning the p53 status of cells (8). We analyzed responses to $\mathrm{CoCl}_{2}$ exposure over time ( 0 to $24 \mathrm{~h}$ ) for two neuroblastoma

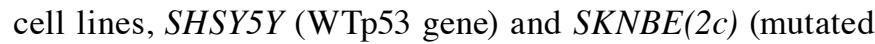
p53 gene). Exposure to $0.5 \mathrm{mM} \mathrm{CoCl}_{2}$, induced a cytotoxic effect (delayed for the mutated-p53-SKNBE(2c) cells) in both cell lines, in a time- and dose-dependent manner, leading to morphological and nuclear changes (data not shown), as previously described $(5-7,26)$.

It is well known that $\mathrm{CoCl}_{2}$, the commonly used hypoxia mimetic agent, induces cell death through oxidative stress by increasing ROS generation $(2,31)$. A part of its effect was mediated by stabilizing of HIF1 $\alpha$ and the activation of downstream signaling. As expected, in both the SHSY5Y and $S K N B E(2 c)$ cells $\mathrm{CoCl}_{2}$ treatment induced HIF1 $\alpha$ expression (data not shown). This stabilization inhibits n-myc expression in $\operatorname{SKNBE}(2 c)$ cells where it is overexpressed (32). Recently, Li et al (33) demonstrated that nickel compounds, hypoxia and hypoxia mimetics degraded the c-myc protein through a proteasome pathway in several cancer cell lines. The disappearance of n-myc was compatible with the change observed in $\mathrm{p} 53$ expression after $\mathrm{CoCl}_{2}$ treatment in $\operatorname{SKNBE}(2 c)$ cells.

ROS-mediated DNA damage induced by $\mathrm{CoCl}_{2}$ can promote p53 expression $(10,34)$. The weak p53 level observed in the control $S H S Y 5 Y$ cells, increased strongly after $\mathrm{CoCl}_{2}$ exposure, in agreement with other data $(8,35)$, whereas p53 upregulation by $\mathrm{CoCl}_{2}$ is sometimes controversial (30). The high p53 baseline level in $S K N B E(1)$ and $S K N B E(2 c)$ cells was in agreement with previous data for mutated p53 (36-38). Starting at $2 \mathrm{~h} \mathrm{CoCl}_{2}$ exposure, p53 disappeared in $\operatorname{SKNBE(2c)}$ cells after treatment (39), possibly due to n-myc degradation (it is a transcriptional regulator of p53) through HIF1 $\alpha$ expression.

The p53 phosphorylation is of crucial importance for its ability to elicit the transcriptional activation of its target genes (such as p21, Bax, Puma, etc.) and more particularly on the Ser15 amino acid after various stresses $(40,41)$. With $\mathrm{CoCl}_{2}$ exposure only a weak Western blot signal was observed (35). We therefore used confocal microscopy to analyze the expression and intracellular localization of phospho-p53 Ser15 after $\mathrm{CoCl}_{2}$ exposure. After $6 \mathrm{~h}$ of cobalt exposure, the phosphorylation of Ser15 appeared only in a part of mitochondria of SHSY5Y cells. This could be due to their distribution in all cell cycle phases after $24 \mathrm{~h}$ of pre-culture, as suggested by the phosphorylation of several amino acids in N-Ter (such as Ser15) peaked in G1 (12). The data agree with the movement of $\mathrm{p} 53$ to the mitochondria in response to stress, in a manner independent of its transcriptional capacities (42), whereas its presence in the mitochondria and nucleus after $12 \mathrm{~h}$ of drug exposure corresponded with gene transcriptional activation, and the executive apoptotic phase. In contrast, in $\operatorname{SKNBE}(2 c)$ cells, the weak Ser15-phosphorylation, regardless the duration of treatment, can be explained by the p53 gene mutation.

PUMA (p53-upregulated modulator of apoptosis) p21 and Bax, pro-apoptotic member of the Bcl-2 family, are transcriptionally upregulated by p53 in response to numerous stresses. In SHSY5Y cells after $6 \mathrm{~h}$ of $\mathrm{CoCl}_{2}$ exposure, a significant increase in the level of PUMA and p21 was observed, coherent with cell cycle arrest and subsequent cell death activation. Bax level was slightly enhanced suggesting its low implication in the process, which is debated after hypoxia or hypoxia mimetic $\left(\mathrm{CoCl}_{2}\right)$ treatment (7,43-45). In SHSY5Y cells, we suggest that the early movement of p53 Ser15 to the mitochondria could contribute to the first moderate $\Delta \Psi_{\mathrm{mt}}$ collapse (starting at $6 \mathrm{~h}$ ). The drastic second wave $\Delta \Psi_{\mathrm{mt}}$ decrease (after $12 \mathrm{~h}$ ) could be associated with translocation of pro-apoptotic protein (PUMA) that is downstream of caspase (-9 and -3 ) activation, triggering apoptosis. Data are supported by the $\Delta \Psi_{\mathrm{mt}}$ collapse following hypoxia or hypoxia-mimetic-drug exposure, characterized in different cell types such as leukemic cell lines (5) and astrocyte primary cultures (6). The measurement of caspase- 9 and -3 activities confirmed the difference in cell death signaling between the two neuroblastoma cell lines. In contrast, in $S K N B E(2 c)$ cells after chloride exposure, no significant change in PUMA expression was detected in mutated-p53-SKNBE(2c) cells, and the significant $\Delta \Psi_{\mathrm{mt}}$ collapse detected only after $24 \mathrm{~h}$, induced a very moderate caspase- 9 and -3 activity without caspase- 8 activation (data not shown). The delay could be correlated with the mutated-p53-status. A late caspase-3 activation was previously observed in the same cells after aloe- 
emodin exposure (37). Caspases are unlikely to play a major role in cobalt-induced apoptosis of $\operatorname{SKNBE}(2 c)$ cells. Thus, we studied an alternate downstream mitochondrial pathway, through the AIF. AIF was discovered as a mitochondrial proapoptotic factor, which is translocated first to the cytosol and to the nucleus, and induces cell death signaling (19). $\mathrm{CoCl}_{2}$ has been reported to induce a $\Delta \Psi_{\mathrm{mt}}$ loss, followed by AIF release (2). In $S H S Y 5 Y$ cells, we did not observe any AIF release from the mitochondria to nuclei at different times during $\mathrm{CoCl}_{2}$ treatment. In contrast, in $S K N B E(2 c)$ cells, AIF translocation from the cytosol to nuclei after $24 \mathrm{~h}$ of $\mathrm{CoCl}_{2}$ treatment, could imply an alternate cell death more recently described, a caspase-independent death pathway known as AIF-meditated programmed necrosis $(46,47)$. Consequently, we propose that this cell death pathway is induced in p53-mutated $\operatorname{SKNBE}(2 c)$ cells due to $\mathrm{CoCl}_{2}$ treatment.

Nevertheless, the delay in $\Delta \Psi_{\mathrm{mt}}$ collapse and cell death is not completely explained by AIF-mediated programmed necrosis. It has been shown that $\Delta \Psi_{\mathrm{mt}}$ loss might trigger apoptosis or precede autophagic cell death (48), which is usually considered to be caspase-independent $(21,49)$. We have examined MAP-LC3-II, a well-known autophagic marker, associated with autophagosome vesicle spreading. The weak green fluorescence of the MAP-LC3-II complex observed both in the SHSY5Y and SKNBE(2c) control cells and then in the treated $S H S Y 5 Y$ cells, became significant only in $\operatorname{SKNBE}(2 c)$ cells treated after $12 \mathrm{~h}$ of $\mathrm{CoCl}_{2}$ treatment. In these latter cells, clearly part of the mitochondria co-located with the MAP-LC3-II complex (data not shown), supporting that $\mathrm{CoCl}_{2}$ induces an autophagy of damaged mitochondria. This process induction was backed up by a significant cathepsin B activity only in $\operatorname{SKNBE}(2 c)$ cells attesting a translocation of autophagosomes to lysosomes and constituting markers of organelle activity and of the autophagic process. The $\mathrm{CoCl}_{2}$ treatment induced an autophagic response in $\operatorname{SKNBE}(2 c)$ cells, explaining the delay observed in the cell death process, due to the disability to carry out apoptosis in the absence of a functional p53. To confirm the hypothesis, we knocked down $\mathrm{p} 53$ in SHSY5Y (WT p53 gene) cells by RNA interference (RNAi) technology and we tested significant biological parameters typical of mitochondrial cell death signaling. As presumed, RNAip53 induced changes in cell viability which became less affected by $\mathrm{CoCl}_{2}$ treatment, reduced $\mathrm{p} 53$ expression significantly and its downstream gene, p21, induced a moderate $\Delta \Psi_{\mathrm{mt}}$ collapse and decreased caspase-3 activity comparatively to WT p53 SHSY5Y cells. Under $\mathrm{CoCl}_{2}$ exposure, inducing oxidative stress, non-functional 53 in $S K N B E(2 c)$ or 553 knockdown in $S H S Y 5 Y$ cells promoted a caspase-independent cell death with an AIF release. Whereas, in SHSY5Y (WT p53 gene) cells, $\mathrm{CoCl}_{2}$ exposure led to a classical apoptosis (through the mitochondrial pathway). Our results illustrate the apoptotic response complexity of $\mathrm{CoCl}_{2}$-treated cells, where several types of signaling occur interdependently, according to the implied regulators, and/or could succeed one another in time.

\section{Acknowledgments}

The authors wish to thank to Claire Carrion for her technical help in confocal imaging, Professor Javier S. Castresana for access to biological samples and Dr Cornelia Wilson-Whelan
(University of Manchester, UK) for helpful suggestions and critical reading of the manuscript. Christophe Stenger and Thomas Naves were supported by a fellowship from the 'Conseil Regional du Limousin'.

\section{References}

1. Hervouet E, Cizkova A, Demont J, et al: HIF and reactive oxygen species regulate oxidative phosphorylation in cancer. Carcinogenesis 29: 1528-1537, 2008.

2. Battaglia V, Compagnone A, Bandino A, et al: Cobalt induces oxidative stress in isolated liver mitochondria responsible for permeability transition and intrinsic apoptosis in hepatocyte primary cultures. Int J Biochem Cell Biol 41: 586-594, 2009.

3. Leonard SS, Harris GK and Shi X: Metal-induced oxidative stress and signal transduction. Free Radic Biol Med 37: 1921-1942, 2004.

4. Zeno S, Zaaroor M, Leshiner S, Veenman L and Gavish M: $\mathrm{CoCl}(2)$ induces apoptosis via the $18 \mathrm{kDa}$ translocator protein in U118MG human glioblastoma cells. Biochemistry 48: 4652-4661, 2009.

5. Guo M, Song LP, Jiang Y, Liu W, Yu Y and Chen GQ: Hypoxiamimetic agents desferrioxamine and cobalt chloride induce leukemic cell apoptosis through different hypoxia-inducible factor-1alpha independent mechanisms. Apoptosis 11: 67-77, 2006.

6. Karovic O, Tonazzini I, Rebola N, et al: Toxic effects of cobalt in primary cultures of mouse astrocytes. Similarities with hypoxia and role of HIF-1alpha. Biochem Pharmacol 73: 694-708, 2007.

7. Jung JY and Kim WJ: Involvement of mitochondrial- and Fas-mediated dual mechanism in $\mathrm{CoCl}_{2}$-induced apoptosis of rat PC12 cells. Neurosci Lett 371: 85-90, 2004.

8. Lee M, Lapham A, Brimmell M, Wilkinson H and Packham G: Inhibition of proteasomal degradation of Mcl-1 by cobalt chloride suppresses cobalt chloride-induced apoptosis in HCT116 colorectal cancer cells. Apoptosis 13: 972-982, 2008.

9. Jung JY, Roh KH, Jeong YJ, et al: Estradiol protects PC12 cells against $\mathrm{CoCl}_{2}$-induced apoptosis. Brain Res Bull 76: 579-585, 2008.

10. Liu B, Chen Y and St. Clair DK: ROS and p53: a versatile partnership. Free Radic Biol Med 44: 1529-1535, 2008.

11. Ferecatu I, Rincheval V, Mignotte B and Vayssiere JL: Tickets for p53 journey among organelles. Front Biosci 14: 4214-4228, 2009.

12. Bode AM and Dong Z: Post-translational modification of $\mathrm{p} 53$ in tumorigenesis. Nat Rev Cancer 4: 793-805, 2004.

13. Millau JF, Bastien N and Drouin R: P53 transcriptional activities: a general overview and some thoughts. Mutat Res 681: 118-133, 2009.

14. Lavin MF and Gueven N: The complexity of p53 stabilization and activation. Cell Death Differ 13: 941-950, 2006.

15. Levine AJ: p53, the cellular gatekeeper for growth and division. Cell 88: 323-331, 1997.

16. Vaseva AV and Moll UM: The mitochondrial p53 pathway. Biochim Biophys Acta 1787: 414-420, 2008.

17. Marchenko ND, Wolff S, Erster S, Becker K and Moll UM: Monoubiquitylation promotes mitochondrial p53 translocation. EMBO J 26: 923-934, 2007.

18. Leist M and Jaattela M: Four deaths and a funeral: from caspases to alternative mechanisms. Nat Rev Mol Cell Biol 2: 589-598, 2001.

19. Cande C, Cecconi F, Dessen P and Kroemer G: Apoptosisinducing factor (AIF): key to the conserved caspase-independent pathways of cell death? J Cell Sci 115: 4727-4734, 2002.

20. Kang YH, Yi MJ, Kim MJ, et al: Caspase-independent cell death by arsenic trioxide in human cervical cancer cells: reactive oxygen species-mediated poly(ADP-ribose) polymerase-1 activation signals apoptosis-inducing factor release from mitochondria. Cancer Res 64: 8960-8967, 2004.

21. Thorburn A: Apoptosis and autophagy: regulatory connections between two supposedly different processes. Apoptosis 13: 1-9, 2008.

22. Scherz-Shouval R and Elazar Z: ROS, mitochondria and the regulation of autophagy. Trends Cell Biol 17: 422-427, 2007.

23. Chen Y, McMillan-Ward E, Kong J, Israels SJ and Gibson SB: Oxidative stress induces autophagic cell death independent of apoptosis in transformed and cancer cells. Cell Death Differ 15: 171-182, 2008. 
24. Zuliani T, Duval R, Jayat C, et al: Sensitive and reliable JC-1 and TOTO-3 double staining to assess mitochondrial transmembrane potential and plasma membrane integrity: interest for cell death investigations. Cytometry A 54: 100-108, 2003.

25. Zuliani T, Denis V, Noblesse E, et al: Hydrogen peroxide-induced cell death in normal human keratinocytes is differentiation dependent. Free Radic Biol Med 38: 307-316, 2005.

26. Kotake-Nara E and Saida $\mathrm{K}$ : Characterization of $\mathrm{CoCl}_{2}$-induced reactive oxygen species (ROS): Inductions of neurite outgrowth and endothelin-2/vasoactive intestinal contractor in PC12 cells by $\mathrm{CoCl}_{2}$ are ROS dependent, but those by $\mathrm{MnCl}_{2}$ are not. Neurosci Lett 422: 223-227, 2007.

27. Tweddle DA, Malcolm AJ, Bown N, Pearson AD and Lunec J: Evidence for the development of p53 mutations after cytotoxic therapy in a neuroblastoma cell line. Cancer Res 61: 8-13, 2001

28. Kroemer G and Martin SJ: Caspase-independent cell death. Nat Med 11: 725-730, 2005.

29. Eisenberg-Lerner A, Bialik S, Simon HU and Kimchi A: Life and death partners: apoptosis, autophagy and the cross-talk between them. Cell Death Differ 16: 966-975, 2009.

30. Lee SG, Lee H and Rho HM: Transcriptional repression of the human p53 gene by cobalt chloride mimicking hypoxia. FEBS Lett 507: 259-263, 2001.

31. Ciafre SA, Niola F, Giorda E, Farace MG and Caporossi D: 